ORIGINAL ARTICLE

\title{
Analysis of all Forensic Autopies at Sheikh Zaid Hospital from 2016 to 2020: A Retroscpective Study
}

\author{
FARIHA TARIQ ${ }^{1}$, SUMAIRA SARWAR ${ }^{2}$, KHALID MUKHTAR ${ }^{3}$, SUMMYIA SADIA ${ }^{4}$, SHAHID NADEEM ${ }^{2}$, HUMERA \\ REHMAN ${ }^{2}$, TALHA LAIQUE ${ }^{*}$ \\ ${ }^{1}$ Department of Forensic Medicine, King Edward Medical University, Lahore-Pakistan \\ ${ }^{2}$ Department of Forensic Medicine, Sahiwal Medical College, Sahiwal-Pakistan \\ ${ }^{3}$ Department of Forensic Medicine, Sheikh zayed Medical College, Rahimyar Khan-Pakistan \\ ${ }^{4}$ Department of Forensic Medicine, Sargodha Medical College, Sargodha-Pakistan \\ ${ }^{5}$ Department of Pharmacology, Allama lqbal Medical College, Lahore-Pakistan \\ *Correspondence to: Dr. Talha Laique, Email: talhalaique51@gmail.com, Tel:+92-331-0346682
}

\begin{abstract}
Autopsy can lead to the cause of death most accurately in both natural as well as unnatural deaths.

Purpose: To determine the pattern of deaths seen on autopsy in a tertiary care hospital and to determine the cause of deaths and manners of deaths with special focus of homicidal cases, seen on autopsies in the past few years.

Study Design: Retrospective study.

Methodology: Patients $(n=186)$ were enrolled in present study held at Forensic department, Sheikh Zaid Hospital, Lahore-Pakistan. Data of 186 autopsy cases of 5 years from 2016 to 2020 was entered and analyzed. All the forensic autopsies done at the forensic department, irrespective of the age and gender were included in the study.

Statistical analysis: Data analyzed by SPSS $22.0 \mathrm{v}$.

Results: Most of the patients were of age group 20 to 30 years. Males were $67 \%$ while females were $20 \%$ in present study. Among these 186 cases of autopsy, manner of death was homicidal in $43 \%(n=80)$ autopsies, accidental in $10 \%(n=19)$ and suicidal deaths was in $1.6 \%(n=3)$ while in $34 \%(n=64)$ autopsy cases cause of death cannot be determined.

Conclusion: This study concluded that the cause of death couldn't be determined in around $1 / 3^{\text {rd }}$ autopsies; showing that steps should be taken to improve performance of forensic departments. As young males are mostly involved in criminal acts, illegal activities should be controlled with education and law enforcement.

Key Words: Autopsy, Audit, Manner of Death and Cause of Death.
\end{abstract}

\section{INTRODUCTION}

Autopsy can lead to the cause of death most accurately in both natural as well as unnatural deaths. Mostly cause of death seems obvious as in accidental deaths leading to mechanical injuries. It is important to know the underlying cause as well as the immediate cause, and manner of death. Cause of death can be defined as a factor which can produce an effect and combination of factors invariably resulting in an effect. ${ }^{1}$

Clinical autopsy is regarded as "gold standard" in the determining the cause of the death. Clinical autopsy referral rates have been in decline for several decades in Europe as well as in the USA. Forensic autopsy is mostly done in suspected suicide, homicide, accidental deaths, and drug / alcohol abuse cases. ${ }^{1}$ Any disease or mechanical injury leading to morbid events and death is labeled as 'cause of death'. Studies have shown that in around $1 / 3^{\text {rd }}$ deaths the presumed cause of death is later found wrong. ${ }^{2}$

Homicide is killing of a human by another human. According to the Pakistani Law, it is a murder. ${ }^{1}$ Various patterns of homicidal deaths include assault using sharp, blunt, or fire-arm weapon; strangulation or homicidal hanging; smothering, drowning, burns, poisoning. ${ }^{3}$

With rise in the population and urbanization, number of homicidal death is also increasing; other factors include poverty, un-employment, and illiteracy. Some evil factors like terrorism and drug addiction are significant factors for some specific populations. Major factor behind all the cases of autopsy is 'economic crises', which is the leading cause of all crimes in our society. ${ }^{3,4}$

Young offenders are becoming increasingly violent and this is a cause for concern, as they are future generation. $^{2}$ Studies have shown that cause of death revealed after autopsies was cardiovascular and cerebrovascular lesion in around $40 \%$ and $20 \%$ among all, respectively; and in more than $30 \%$ of cases, declared cause of death before autopsy was wrong. ${ }^{3,4}$

Objective: To determine the pattern of deaths seen on autopsy in a tertiary care hospital and to determine the cause of deaths and manners of deaths with special focus of homicidal cases, seen on autopsies in the past few years.

Methodology: Patients $(n=186)$ were enrolled in present study held at Forensic department, Sheikh Zaid Hospital, Lahore-Pakistan. Data of 186 autopsy cases of 5 years from 2016 to 2020 was entered and analyzed. All the forensic autopsies done at the forensic department, irrespective of the age and gender were included in the study. The data was collected on written Performa from the records of Forensic medicine, Sheikh Zaid hospital, with permission of the authorities. Autopsy cases in which cause of death was determined either by external and internal examination or by histological examination / chemical analysis of viscera were also included in this study. Partially decomposed, advanced decomposed or skeletonized bodies, with no internal or external injuries sufficient to cause death and histological and toxicological 
reports failing to reveal any abnormal findings, were included in the study. Age, gender, location of victim, cause of death and manner of death with areas/regions affected were noted. Samples for histopathology and biochemical examination were taken where required.

Statistical Analysis: Data analyzed by SPSS 22.0v.

Qualitative variables like gender, location of incident, cause of death and manner of death was expressed as frequency and percentages. Quantitative data was expressed as mean and standard deviations.

\section{RESULTS}

Cases with respect to the age, place of residence, cause of death, manner of death and various regions with injuries were seen on forensic autopsy. Various causes of death like through weapons, asphyxia and poisoning were shown in table-1.

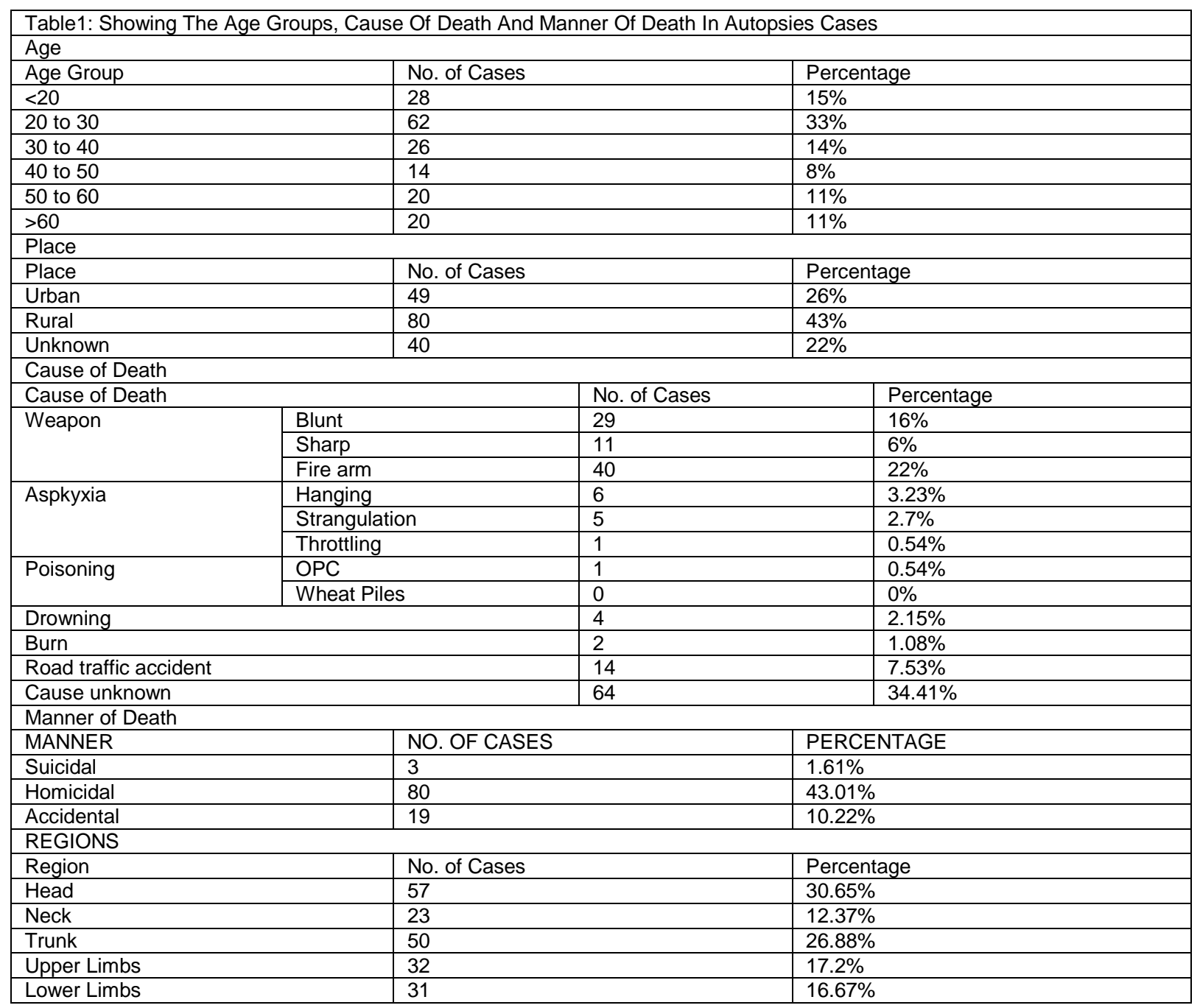

Data was analyzed for manner of death of all the autopsy cases and stratified for age as shown in table-2.

\begin{tabular}{|c|c|c|c|}
\hline \multicolumn{4}{|l|}{ Age versus Manner of Death } \\
\hline \multirow[t]{2}{*}{ Age Group } & \multicolumn{3}{|c|}{ Manner of Death } \\
\hline & Suicidal & Homicidal & Accidental \\
\hline \multirow[t]{2}{*}{$<20$} & 1 & 12 & 4 \\
\hline & $0.54 \%$ & $6.45 \%$ & $2.15 \%$ \\
\hline \multirow[t]{2}{*}{20 to 30} & 1 & 35 & 4 \\
\hline & $0.54 \%$ & $18.82 \%$ & $2.15 \%$ \\
\hline \multirow[t]{2}{*}{30 to 40} & 0 & 14 & 4 \\
\hline & $0.00 \%$ & $7.53 \%$ & $2.15 \%$ \\
\hline \multirow[t]{2}{*}{40 to 50} & 0 & 5 & 0 \\
\hline & $0.00 \%$ & $2.69 \%$ & $0.00 \%$ \\
\hline \multirow[t]{2}{*}{50 to 60} & 1 & 5 & 4 \\
\hline & $0.54 \%$ & $2.69 \%$ & $2.15 \%$ \\
\hline \multirow[t]{2}{*}{$>60$} & 0 & 6 & 3 \\
\hline & $0.00 \%$ & $3.23 \%$ & $1.61 \%$ \\
\hline
\end{tabular}


Data was analyzed for manner of death of all the autopsy cases and stratified for gender as shown in table-3.

\begin{tabular}{|l|l|l|l|}
\hline \multicolumn{2}{|l|}{ Table-3: Stratified Data Of Manner Of Death With Gender For Autopsy Cases } \\
\hline Gender versus Manner of Death \\
\hline \multirow{2}{*}{ Gender } & Manner of Death & Homicidal & Accidental \\
\cline { 2 - 4 } & Suicidal & 53 & 18 \\
\hline \multirow{2}{*}{ Male } & 2 & $28.49 \%$ & $9.68 \%$ \\
\cline { 2 - 4 } & $1.08 \%$ & 19 & 0 \\
\hline \multirow{2}{*}{ Female } & 1 & $10.22 \%$ & $0.00 \%$ \\
\cline { 2 - 4 } & $0.54 \%$ & & \\
\hline
\end{tabular}

\section{DISCUSSION}

Autopsy is regarded as "gold standard" in the determining the cause of the death in cases with natural and un-natural deaths. Forensic autopsy is mostly done in suspected suicide, homicide, accidental deaths, and in cases with history of drug / alcohol abuse. Any disease or mechanical injury leading to morbid events and eventually death of the victim is labeled as 'cause of death'. Studies have shown that in around $1 / 3^{\text {rd }}$ deaths the presumed cause of death is later found wrong. ${ }^{1,3}$ This audit of forensic autopsies in present study showed after analysis that cause of death was determined in around $66 \%$ and cannot be determined in $34 \%$ cases.

Age was further stratified into groups as shown in table-1. This showed that most of the cases in this data belong to 20-30 age group i.e young people and majority were male cases. Almost half of the cases in which cause of death was confirmed, were homicidal, $2^{\text {nd }}$ cause of death was accidental deaths. This data showed that mostly young males of our population were involved in medico-legal cases and criminal activities with homicidal and accidental deaths.

In a local study of Multan, Pakistan done on homicidal deaths, around 400 cases of autopsies were studied, and around $70 \%$ were homicidal cases with male dominance and of the age of 40-60 years. Most common type of weapon on history was firearm (58\%), and second most common was blunt objects $(21 \%)$. Chest was the most commonly involved. These results were similar to our study. ${ }^{2}$

In another study, results are almost similar to the results and comparison in our research. 2025 bodies of homicides were opened for autopsy with male to female ratio of $3: 1$ and fire-arm injury and blunt injury were common causes of death (in around $60 \%$ and $18 \%$ cases). ${ }^{3}$

According to results of another study of Bulgaria, forensic autopsies showed that commonest cause was death due to mechanical factors (53\%), and asphyxia (24.7\%). These mechanical factors include vehicle accidents, fall from heights $(22 \%)$. Manner of death was accidental $62 \%$, suicidal (31\%) and homicidal $7 \%$. More than half of the suicides were due to hanging. These were not similar to our study. ${ }^{4}$

In a similar study done on mothers, analysis of the data of autopsies done to find the cause of maternal deaths showed that the cause of death was determined after autopsy and it was compatible with clinical diagnosis in around $60 \%$ cases, only. In our study we couldn't find data regarding the clinical diagnosis and clinical etiology cause of death. ${ }^{5}$
A study of Faisalabad, Pakistan showed that accidents leading to death were seen as manner of death in $29 \%$ cases, homicides in $50 \%$, suicide $4 \%$ cases. This was similar to that reported by our study. And manner of death couldn't be determined in $14 \%$ autopsies. ${ }^{6}$

Some audits have been done on clinical autopsies as well to correlate the cause of death clinically declared with that confirmed on autopsy. Lanjewar DN, et al reported, after analysis of results of autopsies done in a major hospital in India, that males of age 21 to 40 years age group were commonly involved. Most common cause of death was infections (56\%), followed by cardiovascular diseases (16\%) and neoplasms in (7\%). The disagreement of clinical diagnosis and postmortem reported cause of death was seen in $31 \%$ cases. $^{7}$

The youth in our country is facing medico legal problems along with rape cases. Surveys have shown that the rate of rape cases is 1 in two hours. These incidents are due to socio economic crisis of the young population, leading to even suicidal deaths of rape victims. Steps should be taken to control the criminal activities of our young populations. ${ }^{8}$

In another locally published study it was reported that of 248 autopsies male to female ratio was $2.5: 1$; most common agent leading to death was Firearm, followed by accidents deaths and asphyxia. Qasim M, et al concluded that illegal firearms showed be discouraged and awareness campaigns should be done along with preventive-strategies to keep people safe and to avoid lethal assaults. Male population should be focused as they are prone to such life threatening conditions. ${ }^{9-11}$

Limitations: Present study had number of limitations like small sample size, financial contrains and limited resources This study failed to find the cause of death in $34 \%$ cases due to limited facilities and knowledge.

\section{CONCLUSION}

This study concluded that the cause of death couldn't be determined in around $1 / 3^{\text {rd }}$ autopsies; showing that steps should be taken to improve performance of forensic departments. As young males are mostly involved in criminal acts, illegal activities should be controlled with education and law enforcement.

Author's contribution: FT \& SS: Overall supervision, write up and literature review. KM \& SS: Statistics application analysis literature review, help in write up. SN, HR \& TL: Literature review help in write-up.

Acknowledgements: I am thankful to Allah and my colleagues who made it possible for me. 


\section{REFERENCES}

1. Reddy KS The Essentials of Forensic Medicine and Toxicology Hyderabad, (india). Medicl. Book Company 2010.

2. Aziz F, Kamran QA, Ahmad T, Shahzad B, Ahmed M, Ahmad Z. Comparative Audit of Homicidal Deaths in Multan During the Year 2011 \& 2016. APMC 2018;12(4):313-6.

3. Ullah A, Raja A, Hamid A, Khan J Pattern of causes of death in homicidal cases on autopsy in Pakistan Gomal J Med Sci 2014;12:218-21.

4. Dekov DP, Ivanov IN, Kostadinov SD, Popovska SL, Lisaev PI, Dorovski PD. Statistical Analysis of the Forensic Autopsies, Performed in the Department of Forensic Medicine of University Hospital Pleven for the Period 20092013 (A Preliminary Report), Journal of Biomedical and Clinical Research, 2016 ;9(1), 30-36

5. Keskin HL, Üstün $Y$, Sanisoğlu $S$ The value of autopsy to determine the cause of maternal deaths in Turkey Journal of the Turkish German Gynecological Association. 2018;19(4):210-4

6. Naheed K, Nadeem S, Iqbal M, Qasim AP, Sadia S, Siddiqui BA. Medicolegal autopsies; audit of medicolegal autopsies in Faisalabad city. Professional Med J 2019; 26(5):696-70

7. Lanjewar DN, Sheth NS, Lanjewar SD, Wagholikar UL Analysis of causes of death as determined at autopsy in a single institute, the grant medical college and sir J. J. Hospital, Mumbai, India, between 1884 and 1966 Arch Pathol Lab Med. 2020;144:644-9.

8. Umair M. An Overview of Crimes against Women and Children in Pakistan Journal of Public Policy and Admin. 2018;2(8):61-4.

9. Qasim M, Khalid MS, Amjad D, Pal MI. Statistical analysis of forensic autopsies conducted in year 2018 in forensic medicine department, FMU/ AHF, Faisalabad. Professional Med J 2020; 27(10):2199-2202.

10. Malik R, Chughtai BR, Khursheed R, Amanat M, Khan SP, Rizvi S. Pattern of unnatural deaths-an audit of autopsies. J Rawal Med Uni. 2017;21(1):97-9.

11. Parveen $\mathrm{H}$, Naeem M, Pal MI, lqbal J, Hussain I. Unnatural deaths. The Professional Medical Journal. 2018 Feb 10;25(02):321-4. 